\title{
Relationships among Food Group Intakes, Household Expenditure, and Education Attainment in a General Japanese Population: NIPPON DATA2010
}

Tomomi Nagahata $^{1}$, Mieko Nakamura $^{2}$, Toshiyuki Ojima ${ }^{2}$, Imako Kondo ${ }^{3}$, Toshiharu Ninomiya ${ }^{4}$,

Katsushi Yoshita ${ }^{5}$, Yusuke Arai ${ }^{6}$, Takayoshi Ohkubo ${ }^{7}, \mathrm{Keiko} \mathrm{Murakami}^{7}$, Nobuo Nishi ${ }^{8}$,

Yoshitaka Murakami ${ }^{9}$, Naoyuki Takashima ${ }^{10}$, Nagako Okuda ${ }^{11}$, Aya Kadota ${ }^{10,12}$, Naoko Miyagawa ${ }^{10}$,

Keiko Kondo ${ }^{10}$, Tomonori Okamura ${ }^{13}$, Hirotsugu Ueshima ${ }^{10,12}$, Akira Okayama ${ }^{14}$, and Katsuyuki Miura ${ }^{10,12}$, for the NIPPON DATA2010 Research Group*

${ }^{1}$ Department of Nutrition, School of Health and Nutrition, Tokaigakuen University, Aichi, Japan

${ }^{2}$ Department of Community Health and Preventive Medicine, Hamamatsu University School of Medicine, Shizuoka, Japan

${ }^{3}$ Department of Food and Nutritional Sciences, College of Bioscience and Biotechnology, Chubu University, Aichi, Japan

${ }^{4}$ Department of Epidemiology and Public Health, Graduate School of Medical Sciences, Kyushu University, Fukuoka, Japan

${ }^{5}$ Department of Food and Human Health Science, Osaka City University Graduate School of Human Life Science, Osaka, Japan

${ }^{6}$ Department of Nutrition, Chiba Prefectural University of Health Sciences, Chiba, Japan

${ }^{7}$ Department of Hygiene and Public Health, Teikyo University School of Medicine, Tokyo, Japan

${ }^{8}$ International Center for Nutrition and Information, National Institute of Health and Nutrition, National Institutes of Biomedical Innovation,

Health and Nutrition, Tokyo, Japan

${ }^{9}$ Department of Medical Statistics, School of Medicine, Toho University, Tokyo, Japan

${ }^{10}$ Department of Public Health, Shiga University of Medical Science, Shiga, Japan

${ }^{11}$ Department of Health and Nutrition, University of Human Arts and Sciences, Saitama, Japan

${ }^{12}$ Center for Epidemiologic Research in Asia, Shiga University of Medical Science, Shiga, Japan

${ }^{13}$ Department of Preventive Medicine and Public Health, Keio University School of Medicine, Tokyo, Japan

${ }^{14}$ Research Institute of Strategy for Prevention, Tokyo, Japan

Received October 4, 2017; accepted October 6, 2017; released online March 5, 2018

\begin{abstract}
Background: A lower socioeconomic status (SES) may be related to the intake of unhealthy food; however, this relationship has not been examined in detail. This study was undertaken to examine relationships among food group intakes and SES in a representative Japanese population.

Methods: This was a cross-sectional study using the baseline data of NIPPON DATA2010, which is a prospective cohort study of the National Health and Nutrition Survey in Japan. A total of 2,898 participants were included in the baseline survey in 2010. The effects of age ( $<65$ years and $\geq 65$ years), equivalent household expenditure (EHE), and education attainment on food group intakes (gram per $1,000 \mathrm{kcal}$ ) were analyzed using a two-way analysis of variance.

Results: When EHE was lower, cereal intake was higher in men and women. Among men, fish, milk, and alcohol intakes were reduced with lower EHE. Among women, vegetable intake was reduced with lower EHE. In men and women, cereal intake was higher with lower education attainment. In contrast, meat intake was reduced with lower education attainment.

Conclusions: Lower SES was associated with a higher cereal intake and lower vegetable, fish, meat, and milk intakes in a representative Japanese population. Socioeconomic discrepancies need to be considered in order to promote healthier dietary habits.
\end{abstract}

Key words: diet; food group; socioeconomic status; equivalent household expenditure; education attainment

Copyright () 2018 Tomomi Nagahata et al. This is an open access article distributed under the terms of Creative Commons Attribution License, which permits unrestricted use, distribution, and reproduction in any medium, provided the original author and source are credited.

\section{INTRODUCTION}

Japanese life expectancy has markedly increased since World War II. This increase may be attributed to a number of factors, one of which is nutritional improvements. Nationwide school lunch programs were initiated in 1954, resulting in increased body weight and height among Japanese children. ${ }^{1}$ Furthermore, daily energy and protein intakes have increased in Japan together with rapid economic growth. ${ }^{1}$ Japan in now in an age of plenty; however, a nutritionally unbalanced diet, mainly comprised of fat,

Address for correspondence. Tomomi Nagahata, Department of Nutrition, School of Health and Nutrition, Tokaigakuen University, 2-901 Nakahira, Tenpaku-ku, Nagoya 468-8514, Japan (e-mail: nagaha-t@tokaigakuen-u.ac.jp).

*Members of NIPPON DATA2010 Research Group are listed in the Appendix of reference 24 
particularly animal fat, and less carbohydrates and vegetables, has emerged as an important public health issue. ${ }^{1}$ A nutritionally unbalanced diet causes high blood pressure and dyslipidemia, which ultimately lead to cardiovascular diseases. ${ }^{2,3}$

The relationship between socioeconomic status (SES) and health has been extensively examined. Several reviews reported that individuals with lower SES have a nutritionally unbalanced diet, such as a diet with low fruit and vegetable intakes. ${ }^{4,5}$ Moreover, individuals with lower SES have higher energy and fat intakes and lower fiber, vitamin (including vitamin C, folates, $\beta$-carotene, and vitamin $\mathrm{D}$ ), and mineral (such as calcium and iron) intakes. ${ }^{5,6}$ Low SES subgroups are known to consume diets of lower monetary value: a lower amount of pulses, vegetables, fruits, fish, meat, and dairy products, and a higher amount of grain, eggs, and fats among Japanese adults. ${ }^{7}$ However, controversy remains regarding the relationships among SES and some food group intakes, such as meat ${ }^{8-11}$ and fish. ${ }^{12-14}$

According to national representative data from the National Diet and Nutrition Survey in the United Kingdom, higher SES (household income, occupational class, and educational attainment) groups have higher fruit and vegetable intakes, but lower red and processed meat and non-milk extrinsic sugar intakes. ${ }^{15}$ In Japan, Nishi et al reported that subjects with a lower household income consumed more cereals, but less vegetables, fruit, mushrooms, fish, meat, and milk products using the data from the National Health and Nutrition Survey (NHNS) ${ }^{16}$ in 2010 and 2011. Dietary data used in the present study were a part of the data analyzed by Nishi et al; however, the relationships among food group intakes, equivalent household expenditure (EHE), and education attainment have not yet been investigated. Therefore, the present study was undertaken to examine the characteristics of food group intakes in relation to SES, EHE, and educational attainment in a representative Japanese population.

\section{METHODS}

\section{Study population}

This was a cross-sectional study based on the National Integrated Project for Prospective Observation of Non-communicable Disease and its Trends in the Aged 2010 (NIPPON DATA2010). NIPPON DATA2010 is a prospective cohort study with the aim of preventing cardiovascular diseases in Japan. The baseline survey was performed at the same time as NHNS in 2010, which was conducted by the Ministry of Health, Labour and Welfare of Japan. Furthermore, these data were linked to the Comprehensive Survey of Living Conditions (CSLC) in June 2010. The details of NHNS2010, ${ }^{17,18}$ CSLC2010, ${ }^{19,20}$ and NIPPON DATA 2010 $21-24$ have been described elsewhere.

Briefly, in November 2010, 8,815 residents aged 1 year and older from 300 randomly selected districts throughout Japan participated in the dietary survey for NHNS2010. Overall, 7,229 participants (3,334 men and 3,895 women) were older than 20 years. A total of 3,873 participants (1,598 men and 2,275 women) had a blood test in NHNS2010, and 2,898 (1,239 men and 1,659 women) agreed to participate in the baseline survey for NIPPON DATA2010. The age distributions of NHNS2010 and NIPPON DATA2010 have already been reported. ${ }^{22}$ The distribution of population by age and sex of NIPPON DATA2010 was similar to that of NHNS2010 with blood tests. In the present study, 2,891 participants (1,236 men and 1,655 women) merged with CSLC2010 were included.
Trained researchers or examiners obtained informed consent from participants before enrolling in the study.

\section{Measurements}

Information on variables for dietary intakes was obtained from the dietary survey for NHNS2010. Dietary intakes were assessed using the "1-day household-based food weighing with approximated proportions method", and the details of this method have been described elsewhere. ${ }^{25}$ In brief, this method was developed to estimate the food intake of individual subjects using a household-based dietary survey. The survey employed a method of approximated proportions of each dish or food shared by family members in the household. All foods were categorized into 98 small groups, 33 medium groups, and 17 large groups in NHNS. In this study, nine groups with relatively high intakes were analyzed among 17 large groups that had a median intake of more than $10 \mathrm{~g}$ : cereals, potatoes and starches (potatoes), soy and soy products including other pulses (soy), vegetables, fruit, fish and shellfish (fish), meat, eggs, and milk products (milk). Moreover, alcohol (including sake, beer, and western liquor) intake was analyzed. Food group intakes were adjusted for total energy intakes using the density method (grams per 1,000 kcal).

EHE, education attainment, and household income per year were surveyed using self-administered questionnaires for CSLC2010, NIPPON DATA2010, and NHNS2010. EHE per month was filled out as household expenses in May, excluding taxes, social security fees, business payments, savings, loans, and life insurances. Of the 2,891 participants, 84 with missing data (29 men and 55 women) and 139 with unknown data (filled out of 999; 51 men and 88 women) were excluded, resulting in 2,668 (1,156 men and 1,512 women) for the analysis. Regarding EHE, household expenses were divided by the square root of the number of household members. In the present study, EHE was reclassified into four categories by sex-specific quartiles (Q1-Q4).

Education attainment was selected from six categories: none, elementary school, junior high school, high school, college, and university. Of the 2,891 participants, 6 were missing data (5 men and 1 woman) and were excluded, resulting in 2,885 (1,231 men and 1,654 women) for the analysis. In the present study, education attainment was reclassified into three categories: $\leq$ junior high school, high school, and college or university.

Household annual income was selected from four categories: $<2$ million yen, 2-6 million yen, $\geq 6$ million yen, and "Don't know". Of the 2,891 participants, 173 were missing data (65 men and 108 women) and 122 had unknown data (filled out "Don't know"; 46 men and 76 women) on household income and were excluded, resulting in 2,596 (1,125 men and 1,471 women) for the analysis on household income. Household income was adjusted by household size; the square root of the number of household members, instead of calculating individual household incomes.

\section{Statistical analysis}

Age was divided into 2 groups: $<65$ years (younger) and $\geq 65$ years (older). The effects of age, EHE, education attainment, and household income on food group intakes were analyzed using a two-way analysis of variance (ANOVA). Concurrently, the interactions between EHE or educational attainment or household income and age were also analyzed. Analyses were performed using IBM SPSS Statistics version 22.0 (Tokyo, Japan). All tests with a difference of $P<0.05$ were considered to be significant. 
Nagahata T, et al.

Table 1. Number (\%) of participants by equivalent household expenditure and education attainment: NIPPON DATA2010

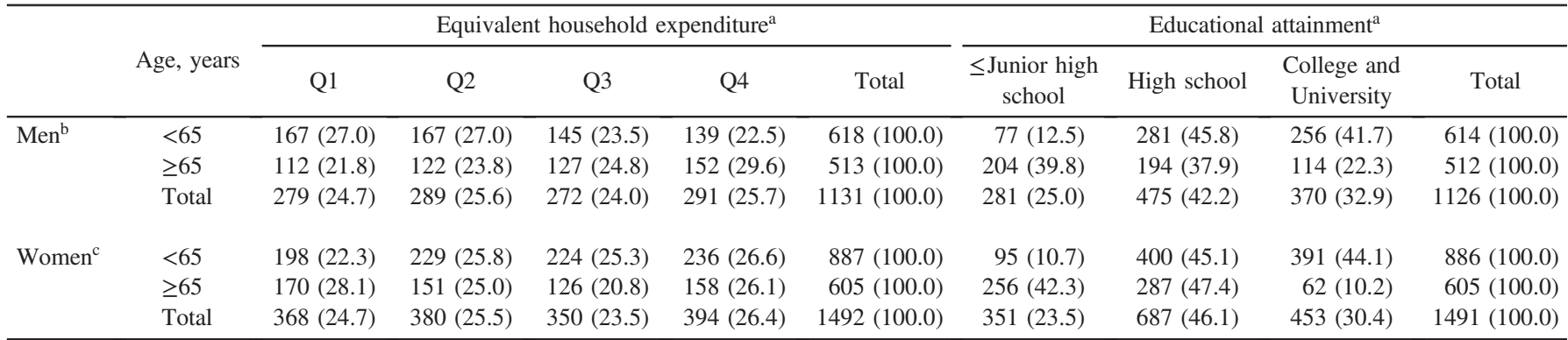

${ }^{\mathrm{a}} n(\%)$.

${ }^{\mathrm{b}}$ Q1-Q4 show quartiles for men, Q1: $\leq 89.5$, Q2: 89.6-132.9, Q3: 133.0-175.1, Q4: $\geq 175.2$ (thousand Yen per month).

${ }^{\mathrm{C}} \mathrm{Q} 1-\mathrm{Q} 4$ show quartiles for women, Q1: $\leq 90.1, \mathrm{Q} 2:$ 90.2-135.1, Q3: 135.2-175.1, Q4: $\geq 175.2$ (thousand Yen per month).

\section{Ethical considerations}

The NIPPON DATA2010 protocol was approved by the Institutional Review Board of Shiga University of Medical Science (No. 22-29, 2010).

\section{RESULTS}

Table 1 shows the distribution of subjects by EHE quartile or education attainment in each age group by sex in 2010. The mean numbers of male household members were Q1: 3.14 (SD, 1.67), Q2: 2.99 (SD, 1.43), Q3: 2.98 (SD, 1.38), and Q4: 2.64 (SD, 1.42), while the mean numbers of female household members were Q1: 2.94 (SD, 1.61), Q2: 2.93 (SD, 1.41), Q3: 2.97 (SD, 1.42), and Q4: 2.61 (SD, 1.34).

Table 2 shows the mean values of 10 food group intakes by the quartiles of EHE. Cereal intake correlated with EHE in men and women. Cereal intake was higher with lower EHE in men and women. Among men, fish, milk, and alcohol intakes were reduced with lower EHE. Among women, vegetable intake was reduced with lower EHE. On the other hand, many food group intakes correlated with age. Among men, younger participants ( $<65$ years) consumed less soy, vegetables, fruit, fish, and milk than older participants ( $\geq 65$ years). Among women, younger participants consumed less potatoes, soy, vegetables, fruit, and fish than older participants. In contrast, younger participants consumed more meat and alcohol than older participants in men and women.

The intake of alcohol in men and fruit in women showed a significant interaction between EHE and age. Alcohol intake was reduced with lower EHE among younger men but not older men. Fruit intake was higher with lower EHE among older women but not younger women.

In comparisons with effects by household income, eTable 1 shows the distribution of subjects by household income in each age group by sex in 2010. eTable 2 shows relationships among food group intakes and household income. Cereal and meat intakes correlated with household income in men and women, whereas meat intake did not correlate with EHE.

Table 3 shows the relationships among food group intakes and education attainment. Cereal and meat intakes correlated with education attainment in men and women. Cereal intake was higher with lower education attainment. In contrast, meat intake was reduced with lower education attainment. Fish intake correlated with education attainment in women. Fish intake was higher with lower education attainment. On the other hand, many food group intakes correlated with age. The relationships among food group intakes and age were similar to those shown in Table 2.

Some food group intakes-fruit and meat in men and fruit and cereals in women-exhibited a significant interaction between education attainment and age. In younger men and women, fruit intake was higher with lower education attainment. In contrast, in older men and women, fruit intake was reduced with lower education attainment.

Since EHE and education attainment may differ by location, the analyses of this study were also conducted by adjusting for area blocks; however, this did not markedly affect the results obtained.

\section{DISCUSSION}

In this study on a representative Japanese population, we examined the intakes of nine food groups and alcohol in relation to EHE and education attainment. Cereal intake was higher with lower EHE in men and women. Furthermore, milk intake in men and vegetable intake in women were reduced with lower EHE. Cereal intake was higher and meat intake was reduced with lower education attainment in men and women.

Nishi et al reported that cereal intake was higher, while vegetable, fruit, mushroom, fish and shellfish, meat, and milk product intakes were lower in the low-household-income group. ${ }^{16}$ In the present study, cereal intake was also higher with lower EHE, while meat intake was reduced with lower educational attainment. To the best of our knowledge, this is the first study to examine food group intakes by education attainment in a general Japanese population, except for a study of Japanese women during pregnancy. ${ }^{26}$ According to a review conducted by Darmon and Drewnowski, ${ }^{5}$ the intake of grains and starchy vegetables (including bread, pasta, rice, and cereals) was high among lowSES individuals. Our results on cereal intake were consistent with these findings. In Japan, lower neighborhood SES has been associated with a higher cereal intake. ${ }^{16}$ Moreover, in this study, meat intake was reduced with low education attainment and household income (eTable 2), which is consistent with previous findings from Western countries ${ }^{8,9}$ and Japan. ${ }^{7,16}$ However, contrasting findings have also been reported. ${ }^{11,12}$ Since dietary habits are affected by population groups, religion, and residence, the relationships among meat intake and SES warrant further study.

In this study, meat intake was reduced with a lower household income but not lower EHE. Higher EHE has been associated with 
Food Group Intakes and Socioeconomic Status

Table 2. Relationships among food group intakes and equivalent household expenditure: NIPPON DATA2010

\begin{tabular}{|c|c|c|c|c|c|c|c|c|c|c|c|c|c|c|c|}
\hline & \multirow{3}{*}{$\begin{array}{l}\text { Age, } \\
\text { years }\end{array}$} & \multicolumn{7}{|c|}{ Men } & \multicolumn{7}{|c|}{ Women } \\
\hline & & \multicolumn{5}{|c|}{ Equivalent household expenditure ${ }^{\mathrm{a}, \mathrm{f}}$} & & \multirow{2}{*}{$P^{\mathrm{e}}$} & \multicolumn{5}{|c|}{ Equivalent household expenditure ${ }^{\mathrm{a}, \mathrm{g}}$} & & \multirow{2}{*}{$P^{\mathrm{e}}$} \\
\hline & & Q1 & Q2 & Q3 & Q4 & Total & & & Q1 & Q2 & Q3 & Q4 & Total & & \\
\hline \multirow[t]{3}{*}{ Cereals } & $<65$ & $267(81)^{* \mathrm{~d}}$ & $256(76)^{* d}$ & $245(71)$ & $232(66)$ & $251(75)$ & EHE & $<0.001$ & $235(70)^{* \mathrm{~d}}$ & $219(72)$ & $231(77)^{* d}$ & $204(64)$ & $222(72)$ & EHE & $<0.001$ \\
\hline & $\geq 65$ & $256(73)^{* d}$ & $256(75)^{* d}$ & $242(73)$ & $221(64)$ & $242(72)$ & Age & 0.131 & $248(72)^{* c, d}$ & $233(69)^{* d}$ & $224(69)$ & $205(58)$ & $228(69)$ & Age & 0.151 \\
\hline & Total & $262(78)^{* \mathrm{c}, \mathrm{d}}$ & $256(75)^{* d}$ & $244(72)^{* \mathrm{~d}}$ & $226(65)$ & $247(74)$ & Interaction & 0.766 & $241(71)^{* b, d}$ & $225(71)^{* d}$ & $229(74)^{* d}$ & $205(62)$ & $224(71)$ & Interaction & 0.128 \\
\hline \multirow[t]{3}{*}{ Potatoes } & $<65$ & $28(32)$ & $27(29)$ & $26(32)$ & $26(32)$ & $27(31)$ & EHE & 0.896 & $30(31)$ & 31 (39) & $28(36)$ & $30(38)$ & $30(36)$ & EHE & 0.678 \\
\hline & $\geq 65$ & $30(35)$ & $30(39)$ & $30(35)$ & $29(34)$ & $30(35)$ & Age & 0.157 & $40(44)$ & 34 (39) & 35 (37) & 39 (37) & $37(40)$ & Age & 0.001 \\
\hline & Total & $29(33)$ & $29(33)$ & $28(33)$ & $28(33)$ & $28(33)$ & Interaction & 0.988 & $35(38)$ & $32(39)$ & $31(37)$ & $34(38)$ & $33(38)$ & Interaction & 0.641 \\
\hline \multirow[t]{3}{*}{ Soy } & $<65$ & $31(40)$ & $29(44)$ & $28(38)$ & $30(33)$ & $30(39)$ & EHE & 0.645 & $40(45)^{* \mathrm{~b}}$ & $28(36)$ & $34(41)$ & $36(43)$ & $34(41)$ & EHE & 0.114 \\
\hline & $\geq 65$ & $40(42)$ & 37 (44) & $39(43)$ & 33 (34) & $37(41)$ & Age & 0.002 & $43(44)$ & $41(44)$ & $38(35)$ & $43(43)$ & $42(42)$ & Age & 0.002 \\
\hline & Total & $35(41)$ & $32(44)$ & $33(41)$ & $31(34)$ & $33(40)$ & Interaction & 0.602 & $42(45)$ & $33(40)$ & $35(39)$ & $38(43)$ & 37 (42) & Interaction & 0.443 \\
\hline \multirow[t]{3}{*}{ Vegetables } & $<65$ & $132(77)$ & 137 (86) & 137 (79) & $138(77)$ & $136(80)$ & EHE & 0.713 & 158 (93) & $156(95)$ & $155(90)$ & $169(91)$ & $160(93)$ & EHE & 0.030 \\
\hline & $\geq 65$ & 159 (106) & $166(87)$ & $161(82)$ & $168(89)$ & $164(91)$ & Age & $<0.001$ & $182(100)^{* \mathrm{~d}}$ & $192(102)$ & $198(92)$ & 213 (109) & $196(102)$ & Age & $<0.001$ \\
\hline & Total & $143(90)$ & 149 (88) & $148(81)$ & $154(85)$ & $148(86)$ & Interaction & 0.984 & $169(97)^{* d}$ & $170(99)$ & $171(93)$ & 187 (101) & $175(98)$ & Interaction & 0.464 \\
\hline \multirow[t]{3}{*}{ Fruit } & $<65$ & $28(50)$ & $34(45)$ & $43(66)$ & $43(51)$ & 37 (53) & EHE & 0.078 & $59(68)$ & $72(84)$ & 64 (79) & $67(67)$ & $66(75)$ & EHE & 0.791 \\
\hline & $\geq 65$ & $71(69)$ & $73(60)$ & $67(62)$ & $82(68)$ & $74(65)$ & Age & $<0.001$ & $101(80)$ & 84 (75) & 90 (77) & $99(72)$ & 94 (76) & Age & $<0.001$ \\
\hline & Total & $45(62)$ & $51(55)$ & $54(65)$ & $63(63)$ & $54(62)$ & Interaction & 0.249 & 79 (76) & $77(81)$ & $73(80)$ & $79(71)$ & 77 (77) & Interaction & 0.062 \\
\hline \multirow[t]{3}{*}{ Fish } & $<65$ & $37(38)$ & $34(33)$ & $42(40)$ & $43(32)$ & $39(36)$ & EHE & 0.015 & $40(41)$ & $38(37)$ & $40(40)$ & 44 (37) & 41 (39) & EHE & 0.079 \\
\hline & $\geq 65$ & $52(44)$ & $44(32)$ & $52(39)$ & $55(40)$ & $51(39)$ & Age & $<0.001$ & $46(39)$ & $44(51)$ & $44(34)$ & $52(35)$ & $47(40)$ & Age & 0.004 \\
\hline & Total & $43(41)$ & $38(33)^{* \mathrm{~d}}$ & $47(40)$ & 49 (37) & $44(38)$ & Interaction & 0.789 & $43(40)$ & $40(43)$ & $42(38)$ & 47 (36) & $43(39)$ & Interaction & 0.893 \\
\hline \multirow[t]{3}{*}{ Meat } & $<65$ & $43(36)$ & $46(32)$ & 49 (37) & $46(35)$ & $46(35)$ & EHE & 0.723 & $42(35)$ & $43(32)$ & $43(34)$ & 45 (37) & $43(34)$ & EHE & 0.287 \\
\hline & $\geq 65$ & $30(29)$ & $29(27)$ & $28(25)$ & $32(26)$ & $30(27)$ & Age & $<0.001$ & $28(28)$ & $31(27)$ & $34(25)$ & $32(28)$ & $31(27)$ & Age & $<0.001$ \\
\hline & Total & $38(34)$ & $39(32)$ & 39 (34) & $39(31)$ & $39(32)$ & Interaction & 0.479 & $35(32)$ & $39(30)$ & $40(32)$ & $40(34)$ & $38(32)$ & Interaction & 0.946 \\
\hline \multirow[t]{3}{*}{ Eggs } & $<65$ & $20(18)$ & $17(15)$ & $18(17)$ & $17(16)$ & $18(16)$ & EHE & 0.440 & $20(20)$ & $21(21)$ & $18(17)$ & $20(17)$ & $20(19)$ & EHE & 0.589 \\
\hline & $\geq 65$ & $18(16)$ & $18(17)$ & $16(17)$ & $18(16)$ & $18(17)$ & Age & 0.894 & $18(19)$ & $21(21)$ & $22(21)$ & $19(18)$ & $20(20)$ & Age & 0.966 \\
\hline & Total & $19(17)$ & 17 (16) & 17 (17) & $18(16)$ & $18(17)$ & Interaction & 0.685 & $19(20)$ & $21(21)$ & 19 (19) & 19 (18) & $20(19)$ & Interaction & 0.158 \\
\hline \multirow[t]{3}{*}{ Milk } & $<65$ & $30(48)$ & $40(55)$ & $37(58)$ & $45(57)$ & $38(55)$ & EHE & $<0.001$ & $56(71)$ & $70(72)$ & $61(72)$ & $66(75)$ & $63(73)$ & EHE & 0.050 \\
\hline & $\geq 65$ & $35(53)^{* b, d}$ & 57 (67) & $50(61)$ & 69 (67) & $54(64)$ & Age & $<0.001$ & $58(70)$ & $70(70)$ & $62(71)$ & $72(67)$ & 66 (69) & Age & 0.571 \\
\hline & Total & $32(50)^{* b, d}$ & $47(61)$ & $43(60)$ & 57 (64) & $45(59)$ & Interaction & 0.257 & $57(70)$ & $70(71)$ & $62(72)$ & $68(72)$ & $64(71)$ & Interaction & 0.923 \\
\hline \multirow[t]{3}{*}{ Alcohol } & $<65$ & $80(129)^{* \mathrm{c}}$ & $77(133)^{* \mathrm{c}}$ & $158(220)$ & $111(160)$ & 105 (165) & EHE & $<0.001$ & 27 (97) & 38 (115) & $33(93)$ & 41 (101) & $35(102)$ & EHE & 0.119 \\
\hline & $\geq 65$ & 71 (106) & $90(146)$ & 87 (138) & $100(145)$ & 88 (136) & Age & 0.043 & $10(39)$ & $21(70)$ & $9(34)$ & $21(72)$ & $16(57)$ & Age & $<0.001$ \\
\hline & Total & $77(120)^{* \mathrm{c}}$ & $82(138)^{* \mathrm{c}}$ & 125 (189) & $106(152)$ & 97 (153) & Interaction & 0.007 & $19(76)$ & $31(100)$ & $24(78)$ & $33(91)$ & $27(87)$ & Interaction & 0.937 \\
\hline
\end{tabular}

EHE, equivalent household expenditure.

${ }^{\mathrm{a} M e a n s}$ (SD) (g/1,000 kcal).

${ }^{* b}$ Multiple comparisons compared with Q2, $P<0.05$.

${ }^{* c}$ Multiple comparisons compared with Q3, $P<0.05$.

${ }^{* \mathrm{~d}}$ Multiple comparisons compared with $\mathrm{Q} 4, P<0.05$.

eMain effect or interaction by ANOVA, adjusted by the type of house.

${ }^{\mathrm{f}} \mathrm{Q} 1-\mathrm{Q} 4$ show quartiles for men, Q1: $\leq 89.5$, Q2: 89.6-132.9, Q3: 133.0-175.1, Q4: $\geq 175.2$ (thousand Yen per month).

${ }^{\mathrm{g}} \mathrm{Q} 1-\mathrm{Q} 4$ show quartiles for women, Q1: $\leq 90.1, \mathrm{Q} 2:$ 90.2-135.1, Q3: 135.2-175.1, Q4: $\geq 175.2$ (thousand Yen per month).

a balanced nutritional intake in Japanese adults. ${ }^{27}$ However, this is the first study on food group intakes by EHE. In this study, EHE was reduced with a lower household income in this population (data not shown); however, some of this population had higher EHE due to savings in part from the elderly with a lower household income. Therefore, the population with a higher household income may differ from that with higher EHE.

In this study, fruit intake exhibited a significant interaction between education attainment and age. Among elderly men and women, fruit intake was lower in participants with less than junior high school education than those more education. Correspondingly, a previous study reported that women obtaining higher education qualifications consumed more fruit and vegetables. ${ }^{28}$ Nakamura et al found that a higher education correlated with a greater vegetable intake using information on nutrition labels and conversations with family or friends during meals in Japanese adults. ${ }^{29}$ Based on these findings, highly educated individuals appear to have learned more about healthy food habits in the school period, resulting in higher vegetable and fruit intakes. Among younger men and women, however, fruit intake was higher in participants with less than junior high school education than those more education, and we did not take this into consideration as a confounding factor. Different factors between younger and older individuals may mediate fruit intake.

There are two main limitations in this study. The design of this study was cross-sectional. Therefore, our data do not explain any causal relationships among SES and food group intakes. Furthermore, the dietary intake survey for NHNS was performed on 1 day in November. Therefore, marketing variance by season may affect food group intakes in this study.

Beyond these limitations, it is important that cereal intake was higher with lower EHE and educational attainment. Moreover, meat intake was reduced among those with lower educational attainment using the national survey in Japan. Socioeconomic discrepancies need to be considered in order to promote healthier dietary habits. 
Table 3. Relationships among food group intakes and education attainment: NIPPON DATA2010

\begin{tabular}{|c|c|c|c|c|c|c|c|c|c|c|c|c|c|}
\hline & \multirow{3}{*}{$\begin{array}{l}\text { Age, } \\
\text { years }\end{array}$} & \multicolumn{6}{|c|}{ Men } & \multicolumn{6}{|c|}{ Women } \\
\hline & & \multicolumn{4}{|c|}{ Educational attainment ${ }^{\mathrm{a}}$} & & \multirow[b]{2}{*}{$P^{\mathrm{d}}$} & \multicolumn{4}{|c|}{ Educational attainment ${ }^{\mathrm{a}}$} & & \multirow[b]{2}{*}{$P^{\mathrm{d}}$} \\
\hline & & $\begin{array}{c}\leq \text { Junior } \\
\text { high school }\end{array}$ & High school & $\begin{array}{l}\text { College and } \\
\text { University }\end{array}$ & Total & & & $\begin{array}{c}\leq \text { Junior } \\
\text { high school }\end{array}$ & High school & $\begin{array}{l}\text { College and } \\
\text { University }\end{array}$ & Total & & \\
\hline \multirow[t]{3}{*}{ Cereals } & $<65$ & $269(78)^{* \mathrm{c}}$ & $253(76)$ & $245(72)$ & $251(75)$ & Education attainment & $<0.001$ & $234(72)$ & $218(72)$ & $223(72)$ & $222(72)$ & Education attainment & $<0.001$ \\
\hline & $\geq 65$ & $254(76)^{* \mathrm{c}}$ & $242(66)^{* \mathrm{c}}$ & $219(69)$ & $242(72)$ & Age & $<0.001$ & $246(71)^{* b, c}$ & $220(63)^{* c}$ & $193(69)$ & $228(69)$ & Age & 0.243 \\
\hline & Total & $258(76)^{* b, c}$ & $248(72)^{* \mathrm{c}}$ & $237(72)$ & $247(74)$ & Interaction & 0.392 & $243(72)^{* b, c}$ & $219(68)$ & $219(72)$ & $224(71)$ & Interaction & 0.002 \\
\hline \multirow[t]{3}{*}{ Potatoes } & $<65$ & $28(31)$ & $26(30)$ & $27(32)$ & $27(31)$ & Education attainment & 0.376 & $32(40)$ & $32(38)$ & $28(34)$ & $30(36)$ & Education attainment & 0.416 \\
\hline & $\geq 65$ & $32(38)$ & $27(31)$ & $31(38)$ & $30(35)$ & Age & 0.183 & $38(42)$ & 37 (38) & $34(35)$ & $37(40)$ & Age & 0.018 \\
\hline & Total & $31(36)$ & $26(30)$ & $28(34)$ & $28(33)$ & Interaction & 0.755 & $36(42)$ & $34(38)$ & $29(34)$ & $33(38)$ & Interaction & 0.984 \\
\hline \multirow[t]{3}{*}{ Soy } & $<65$ & $37(43)$ & $27(35)$ & $30(42)$ & $29(39)$ & Education attainment & 0.097 & $34(41)$ & $34(39)$ & $35(44)$ & $34(41)$ & Education attainment & 0.718 \\
\hline & $\geq 65$ & $39(42)$ & $35(37)$ & $37(43)$ & $37(41)$ & Age & 0.031 & $39(44)$ & $43(41)$ & $45(40)$ & $42(42)$ & Age & 0.003 \\
\hline & Total & $38(42)$ & $30(36)$ & $32(42)$ & $33(40)$ & Interaction & 0.706 & $38(43)$ & $38(40)$ & $36(44)$ & $37(42)$ & Interaction & 0.818 \\
\hline \multirow[t]{3}{*}{ Vegetables } & $<65$ & $140(96)$ & $132(77)$ & $139(78)$ & $136(80)$ & Education attainment & 0.073 & $158(96)$ & $160(91)$ & $160(93)$ & $160(93)$ & Education attainment & 0.264 \\
\hline & $\geq 65$ & $163(90)$ & $157(92)$ & $178(87)$ & $164(91)$ & Age & $<0.001$ & $185(101)^{* b}$ & $206(101)$ & 197 (102) & $196(102)$ & Age & $<0.001$ \\
\hline & Total & $157(92)$ & $142(84)$ & $151(83)$ & $148(86)$ & Interaction & 0.448 & $178(101)$ & $179(98)$ & $165(95)$ & $175(98)$ & Interaction & 0.336 \\
\hline \multirow[t]{3}{*}{ Fruit } & $<65$ & $44(53)$ & $35(54)$ & $37(53)$ & $37(53)$ & Education attainment & 0.112 & $81(95)$ & $62(67)$ & $66(78)$ & $66(75)$ & Education attainment & 0.931 \\
\hline & $\geq 65$ & $67(66)^{* \mathrm{c}}$ & $73(62)$ & $88(67)$ & $74(65)$ & Age & $<0.001$ & $86(77)$ & $101(78)$ & $98(63)$ & $94(76)$ & Age & $<0.001$ \\
\hline & Total & $61(63)$ & $50(60)$ & $53(63)$ & $54(62)$ & Interaction & 0.018 & $84(82)$ & 78 (74) & 71 (77) & 77 (77) & Interaction & 0.007 \\
\hline \multirow[t]{3}{*}{ Fish } & $<65$ & $41(37)$ & $40(37)$ & $38(35)$ & $39(36)$ & Education attainment & 0.511 & $52(41)^{* \mathrm{c}}$ & $43(40)^{* \mathrm{c}}$ & $36(36)$ & $41(39)$ & Education attainment & 0.018 \\
\hline & $\geq 65$ & $51(40)$ & $52(39)$ & $48(35)$ & $51(39)$ & Age & $<0.001$ & $48(46)$ & $46(36)$ & $44(31)$ & $47(40)$ & Age & 0.302 \\
\hline & Total & $49(40)$ & $45(38)$ & $41(35)$ & $44(38)$ & Interaction & 0.939 & $49(45)^{* \mathrm{c}}$ & $44(38)$ & $37(35)$ & $43(39)$ & Interaction & 0.235 \\
\hline \multirow[t]{3}{*}{ Meat } & $<65$ & $33(27)^{* \mathrm{~b}, \mathrm{c}}$ & $46(36)$ & $50(35)$ & $46(35)$ & Education attainment & 0.001 & $30(29)^{* b, c}$ & $44(34)$ & $47(36)$ & $43(35)$ & Education attainment & $<0.001$ \\
\hline & $\geq 65$ & $28(27)$ & $32(27)$ & $31(25)$ & $30(27)$ & Age & $<0.001$ & $26(27)^{* b}$ & $35(27)$ & $35(26)$ & $31(27)$ & Age & $<0.001$ \\
\hline & Total & $29(27)^{* b, c}$ & $40(33)$ & $44(33)$ & $39(32)$ & Interaction & 0.046 & $27(28)^{* b, c}$ & $40(31)$ & $45(35)$ & $38(32)$ & Interaction & 0.461 \\
\hline \multirow[t]{3}{*}{ Eggs } & $<65$ & $19(20)$ & $18(16)$ & $18(15)$ & $18(16)$ & Education attainment & 0.744 & $22(22)$ & $20(19)$ & $19(18)$ & $20(19)$ & Education attainment & 0.552 \\
\hline & $\geq 65$ & $18(17)$ & $17(17)$ & $18(16)$ & $18(17)$ & Age & 0.731 & $20(22)$ & $20(18)$ & $19(17)$ & $20(20)$ & Age & 0.529 \\
\hline & Total & $18(18)$ & $18(16)$ & $18(16)$ & $18(17)$ & Interaction & 0.876 & $20(22)$ & $20(18)$ & $19(18)$ & $20(19)$ & Interaction & 0.848 \\
\hline \multirow[t]{3}{*}{ Milk } & $<65$ & $33(54)$ & $36(54)$ & $41(56)$ & $38(55)$ & Education attainment & 0.088 & $62(76)$ & $63(74)$ & $65(71)$ & $64(73)$ & Education attainment & 0.175 \\
\hline & $\geq 65$ & $45(63)^{* b}$ & $61(66)$ & $58(58)$ & $54(64)$ & Age & $<0.001$ & $56(67)^{* \mathrm{~b}}$ & $73(71)$ & $72(67)$ & $66(69)$ & Age & 0.415 \\
\hline & Total & $42(61)$ & $47(60)$ & $46(57)$ & $45(59)$ & Interaction & 0.376 & $57(69)$ & $67(73)$ & $66(70)$ & $64(71)$ & Interaction & 0.289 \\
\hline \multirow[t]{3}{*}{ Alcohol } & $<65$ & $109(182)$ & $111(165)$ & $96(161)$ & $105(165)$ & Education attainment & 0.772 & $42(173)$ & $34(91)$ & $34(89)$ & 35 (102) & Education attainment & 0.813 \\
\hline & $\geq 65$ & $96(140)$ & 76 (123) & 96 (147) & 88 (136) & Age & 0.106 & $15(53)$ & $15(59)$ & $18(63)$ & $16(57)$ & Age & $<0.001$ \\
\hline & Total & 99 (153) & 97 (150) & 96 (156) & 97 (153) & Interaction & 0.270 & $23(101)$ & $26(80)$ & $32(86)$ & 27 (87) & Interaction & 0.753 \\
\hline
\end{tabular}

${ }^{\mathrm{a}}$ Means (SD) (g/1,000 kcal).

${ }^{* \mathrm{~b}}$ Multiple comparisons compared with High school, $P<0.05$.

${ }^{* \mathrm{c}}$ Multiple comparisons compared with College and University, $P<0.05$.

${ }^{\mathrm{d}}$ Main effect or interaction by ANOVA.

\section{ACKNOWLEDGMENTS}

We deeply appreciate the Japanese Association of Public Health Center Directors and the Japan Medical Association for their support with NIPPON DATA2010's baseline and follow-up survey. We also appreciate Shionogi Co., Ltd. for their support measuring brain natriuretic peptide. We also thank the staffs of the Japanese public health centers and medical examination institutions listed in the Appendix of the reference 24.

Funding sources: This study was supported by Health and Labour Sciences Research Grants of the Ministry of Health, Labour and Welfare, Japan (Comprehensive Research on LifeStyle Related Diseases including Cardiovascular Diseases and Diabetes Mellitus [H22-Junkankitou-Seishuu-Sitei-017, H25Junkankitou-Seishuu-Sitei-022]).

Conflicts of interest: None declared.

\section{APPENDIX A. SUPPLEMENTARY DATA}

Supplementary data related to this article can be found at https:// doi.org/10.2188/jea.JE20170248.

\section{REFERENCES}

1. Sugiura Y, Ju YS, Yasuoka J, et al. Rapid increase in Japanese life expectancy after World War II. Biosci Trends. 2010;4:9-16.

2. Ndanuko RN, Tapsell LC, Charlton KE, et al. Dietary patterns and blood pressure in adults: a systematic review and meta-analysis of randomized controlled trials. Adv Nutr. 2016;7:76-89.

3. Tada N, Maruyama C, Koba S, et al. Japanese dietary lifestyle and cardiovascular disease. J Atheroscler Thromb. 2011;18:723-734.

4. James WP, Nelson M, Ralph A, et al. Socioeconomic determinants of health. The contribution of nutrition to inequalities in health. BMJ. 1997;314:1545-1549.

5. Darmon N, Drewnowski A. Does social class predict diet quality? Am J Clin Nutr. 2008;87:1107-1117.

6. Novaković R, Cavelaars A, Geelen A, et al. Socio-economic determinants of micronutrient intake and status in Europe: a systematic review. Public Health Nutr. 2014;17:1031-1045.

7. Okubo H, Murakami K, Sasaki S. Monetary value of self-reported diets and associations with sociodemographic characteristics and dietary intake among Japanese adults: analysis of nationally representative surveys. Public Health Nutr. 2016;19:3306-3318.

8. Galobardes B, Morabia A, Bernstein MS. Diet and socioeconomic position: does the use of different indicators matter? Int J Epidemiol. 2001;30:334-340. 
9. Hupkens CL, Knibbe RA, Drop MJ. Social class differences in women's fat and fibre consumption: a cross-national study. Appetite. 1997;28:131-149.

10. La Vecchia C, Negri E, Franceschi S, et al. Differences in dietary intake with smoking, alcohol, and education. Nutr Cancer. 1992;17: 297-304.

11. Smith AM, Baghurst KI. Public health implications of dietary differences between social status and occupational category groups. J Epidemiol Community Health. 1992;46:409-416.

12. Worsley A, Blasche R, Ball K, et al. Income differences in food consumption in the 1995 Australian National Nutrition Survey. Eur J Clin Nutr. 2003;57:1198-1211.

13. Mishra G, Ball K, Arbuckle J, et al. Dietary patterns of Australian adults and their association with socioeconomic status: results from the 1995 National Nutrition Survey. Eur J Clin Nutr. 2002;56:687693.

14. Groth MV, Fagt S, Brøndsted L. Social determinants of dietary habits in Denmark. Eur J Clin Nutr. 2001;55:959-966.

15. Maguire ER, Monsivais P. Socio-economic dietary inequalities in UK adults: an updated picture of key food groups and nutrients from national surveillance data. Br J Nutr. 2015;113:181-189.

16. Nishi N, Horikawa C, Murayama N. Characteristics of food group intake by household income in the National Health and Nutrition Survey, Japan. Asia Pac J Clin Nutr. 2017;26:156-159.

17. Ikeda N, Takimoto H, Imai S, et al. Data resource profile: The Japan National Health and Nutrition Survey (NHNS). Int J Epidemiol. 2015;44:1842-1849.

18. Ministry of Health, Labour and Welfare, Japan. The National Health and Nutrition Survey in Japan, 2010. http://www.mhlw.go.jp/ bunya/kenkou/eiyou/dl/h22-houkoku-01.pdf (in Japanese). Accessed 17.01.19.

19. Ikeda N, Shibuya K, Hashimoto H. Improving population health measurement in national household surveys: a simulation study of the sample design of the comprehensive survey of living conditions of the people on health and welfare in Japan. J Epidemiol. 2011;21: 385-390.

20. Ministry of Health, Labour and Welfare, Japan. The Comprehensive Survey of Living Conditions in Japan, 2010. http://www.mhlw.go. jp/toukei/saikin/hw/k-tyosa/k-tyosa10/index.html (in Japanese). Accessed 17.01.19.

21. Michikawa T, Okamura T, Nitta H, et al. Cross-sectional association between exposure to particulate matter and inflammatory markers in the Japanese general population: NIPPON DATA2010. Environ Pollut. 2016;213:460-467.

22. Kogure M, Tsuchiya N, Hozawa A, et al. Does the flushing response modify the relationship between alcohol intake and hypertension in the Japanese population? NIPPON DATA2010. Hypertens Res. 2016;39:670-679.

23. Satoh A, Arima H, Ohkubo T, et al. Associations of socioeconomic status with prevalence, awareness, treatment, and control of hypertension in a general Japanese population: NIPPON DATA2010. J Hypertens. 2017;35:401-408.

24. Kadota A, Okuda N, Ohkubo T, et al. The National Integrated Project for Prospective Observation of Non-communicable Disease and its Trends in the Aged 2010 (NIPPON DATA2010): objectives, design, and population characteristics. $J$ Epidemiol. 2018;28(Suppl 3):S2-S9.

25. Iwaoka F, Yoshiike N, Date C, et al. A validation study on a method to estimate nutrient intake by family members through a householdbased food-weighing survey. J Nutr Sci Vitaminol (Tokyo). 2001;47: 222-227.

26. Murakami K, Miyake Y, Sasaki S, et al. Education, but not occupation or household income, is positively related to favorable dietary intake patterns in pregnant Japanese women: the Osaka Maternal and Child Health Study. Nutr Res. 2009;29:164-172.

27. Fukuda Y, Hiyoshi A. High quality nutrient intake is associated with higher household expenditures by Japanese adults. Biosci Trends. 2012;6:176-182.

28. Thornton LE, Pearce JR, Ball K. Sociodemographic factors associated with healthy eating and food security in socioeconomically disadvantaged groups in the UK and Victoria, Australia. Public Health Nutr. 2014;17:20-30.

29. Nakamura S, Inayama T, Hata K, et al. Association of household income and education with eating behaviors in Japanese adults: a cross-sectional study. BMC Public Health. 2016;16:61. 